\title{
Dynamic Behavior of Organic Thin Films Attached to Carbon Surfaces*
}

\author{
Samuel S. C. $\mathrm{Yu}^{\dagger}$ and Alison J. Downard \\ The MacDiarmid Institute for Advanced Materials and Nanotechnology, Department of Chemistry, \\ University of Canterbury, Private Bag 4800, Christchurch, New Zealand \\ (Received 13 October 2005; Accepted 3 November 2005; Published 14 November 2005)
}

\begin{abstract}
The electrochemical reduction of 4-nitrobenzene diazonium salt has been investigated at carbon electrodes. Glassy carbon and pyrolyzed photoresist films were used as substrates to examine the attached nitrophenyl (NP) thin films using electrochemistry and atomic force microscopy (AFM). NP-films were treated to negative potential excursions in aqueous acidic conditions to electrochemically reduce the NP groups. The voltammetric responses of $\mathrm{Fe}(\mathrm{CN})_{6}^{3-}$ redox probe were recorded, and the film thicknesses monitored by an AFM mechanical scratching method that involves removing a section of the film with an AFM tip and measuring the depth profile of the trench created. A mechanism is proposed to account for the observed film changes.
\end{abstract}

[DOI: $10.1380 /$ ejssnt.2005.294]

Keywords: Carbon; Chemically Modified Electrodes; Cyclic Voltammetry; Atomic Force Microscopy; Surface Modification

\section{INTRODUCTION}

The attachment of organic and biological molecules to a surface is important in the functionalisation of materials in particular for the design of bio- and chemical sensing applications. Surface modification methods via the covalent attachment of molecular species on carbon materials have attracted much attention since the first discovery of electrochemically assisted modification techniques in the early 1990s [1]. The most utilized method for attaching aromatic molecules to carbon surfaces is by the reduction of the corresponding aryl diazonium salt. The generation of aryl radicals that can covalently couple to the electrode surface is a well-established mechanism for the process in both aqueous and non-aqueous preparatory conditions. More recently, it has been demonstrated that the method can be extended to other surfaces such as at semiconductor materials [2] and metals [3]. A number of interesting applications have been described for these grafted layers such as in creating molecular junctions for molecular electronic devices [4] and in the derivatization of nanotubes $[5,6]$.

Molecular species that are attached to an interface can impart specificity and selectivity to the material, thus it is imperative to study the properties of these functional layers. Invaluable information about film properties can be gained using a combination of electrochemistry and AFM measurements. In this work, these techniques been employed to look at NP films grafted to glassy carbon (GC) and pyrolysed photoresist films (PPFs). This preliminary study is focused on the characterization of NP films that are deposited on PPF substrates since it has similar electrochemical behavior to GC and it has a low surface roughness $(<0.5 \mathrm{~nm})$ which facilitates AFM film thickness measurements.

\footnotetext{
* This paper is presented at International Symposium on Surface Science and Nanotechnology (ISSS-4), Saitama, Japan, 14-17 November, 2005.

${ }^{\dagger}$ Corresponding author: samuelscyu@gmail.com
}

\section{EXPERIMENTAL}

Materials: Pyrolysed photoresist films were prepared following methods described previously [7]. In general, two coats of positive photoresist AZ4620 (Clariant) were spin-coated on pre-cut silicon wafers at $3000 \mathrm{rpm}$ and soft-baked for at least $20 \mathrm{~min}$ before pyrolyzing at $1050^{\circ} \mathrm{C}$ for $1 \mathrm{hr}$ in a forming-gas atmosphere. GC electrodes used were from a commercial origin (Tokai Co.). 4-nitrobenezenediazonium tetrafluoroborate was synthesized according to standard diazotization procedures from 4-nitroaniline precursor. Electrodes were modified in 0.1 $\mathrm{M}\left[\mathrm{Bu}_{4} \mathrm{~N}\right] \mathrm{BF}_{4}$ acetonitrile solution containing $1-5 \mathrm{mM}$ diazonium salt.

Electrochemistry: The electrochemical cell and procedures used with GC (diameter $=3.0 \mathrm{~mm}$ ) and $\mathrm{PPF}$ samples has been described in full elsewhere [7]; the geometric area of the PPF working electrode is defined by an O-ring $\left(0.26 \mathrm{~cm}^{2}\right.$ for electrode modification and 0.12 $\mathrm{cm}^{2}$ for subsequent scans at the modified surface). In each case, all scans were performed at a scan rate of 200 $\mathrm{mV} . \mathrm{s}^{-1}$. The secondary electrode was a $\mathrm{Pt}$ wire and the reference was either an SCE (for aqueous solutions) or a $\mathrm{Ag}$ wire pseudo-reference electrode (for acetonitrile solutions). The ferrocene /ferrocenium couple appeared at $E_{1 / 2}=0.50 \mathrm{~V}\left(\mathrm{vs} \mathrm{Ag} / \mathrm{Ag}^{+}\right)$in $0.1 \mathrm{M}\left[\mathrm{Bu}_{4} \mathrm{~N}\right] \mathrm{BF}_{4}$ acetonitrile solution. Solutions for electrochemistry were purged with $\mathrm{N}_{2}$. For PPF samples, the modified surface was thoroughly washed with pure acetonitrile and dried with nitrogen gas. Modified GC was ultrasonicated in pure acetonitrile for $30 \mathrm{~s}$ and dried with nitrogen gas.

Atomic Force Microscopy: The procedure for film depth profiling using an AFM tip to mechanically remove film from the modified PPF surface has been described previously [7]. Briefly, the technique of 'scratching' the modified PPF surface uses a chip configuration that has three silicon cantilever tips, of different lengths. Only two tips are used for these experiments. As one of the two shorter tips approaches the surface to begin a tapping mode scan, the longer tip (not in resonance) imbeds into the surface film and effectively scratches the modifier from the PPF surface. Bare PPF surface, to an average depth of $0.3 \mathrm{~nm}$, is also removed by scratching and hence film thickness data have been adjusted accordingly. Af- 


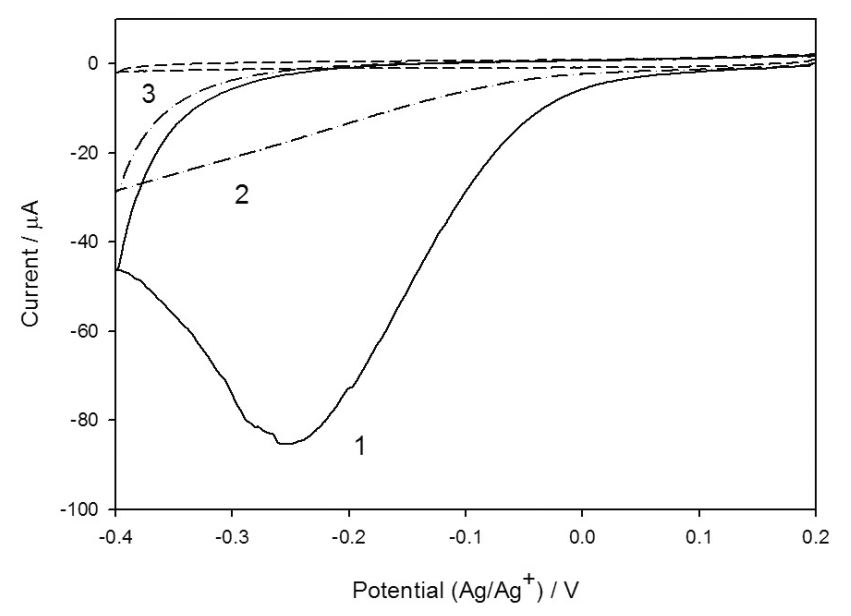

FIG. 1: Cyclic voltammogram for the reduction of $5 \mathrm{mM} 4$ nitrobenzenediazonium tetrafluoroborate in $0.1 \mathrm{M}\left[\mathrm{Bu}_{4} \mathrm{~N}\right] \mathrm{BF}_{4}$ (First, second and final scan after modification at $E_{a p p}$ for 300 s).

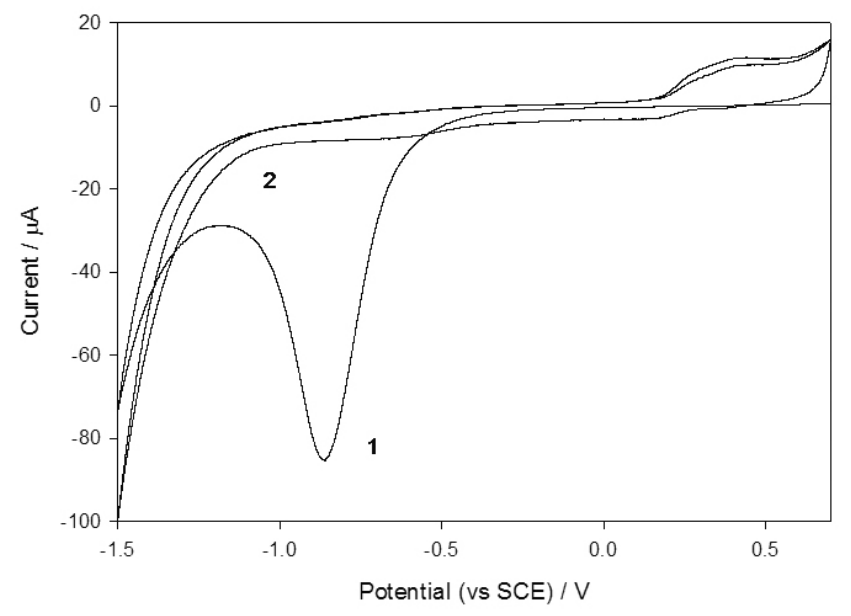

FIG. 2: The cyclic voltammogram in aqueous $0.25 \mathrm{M} \mathrm{H}_{2} \mathrm{SO}_{4}$ of a NP film at PPF generated using modification time of 180 s.

ter removing the film from an area $10 \mu \mathrm{m} \times 1.3 \mu \mathrm{m}$, the tips were withdrawn from the PPF surface and the AFM alignment was refocused onto the longer tip which was used in tapping mode to scan the scratch. Loose debris from the scratch was removed by gentle air convection near the AFM tip. The average cross-sectional plot of the AFM image was used to determine the depth of the film. From the cross-sectional plot, at least 10 paired data points were collected where each pair contained one point from within the scratch and one outside. The height difference of the films was recorded and two new random locations were selected for scratch measurements. The estimated error in the in the paired data points is \pm 0.2 $\mathrm{nm}$. After correction for the scratch depth at bare PPF, all quoted film thickness data have an associated uncertainty of $\pm 0.4 \mathrm{~nm}$.

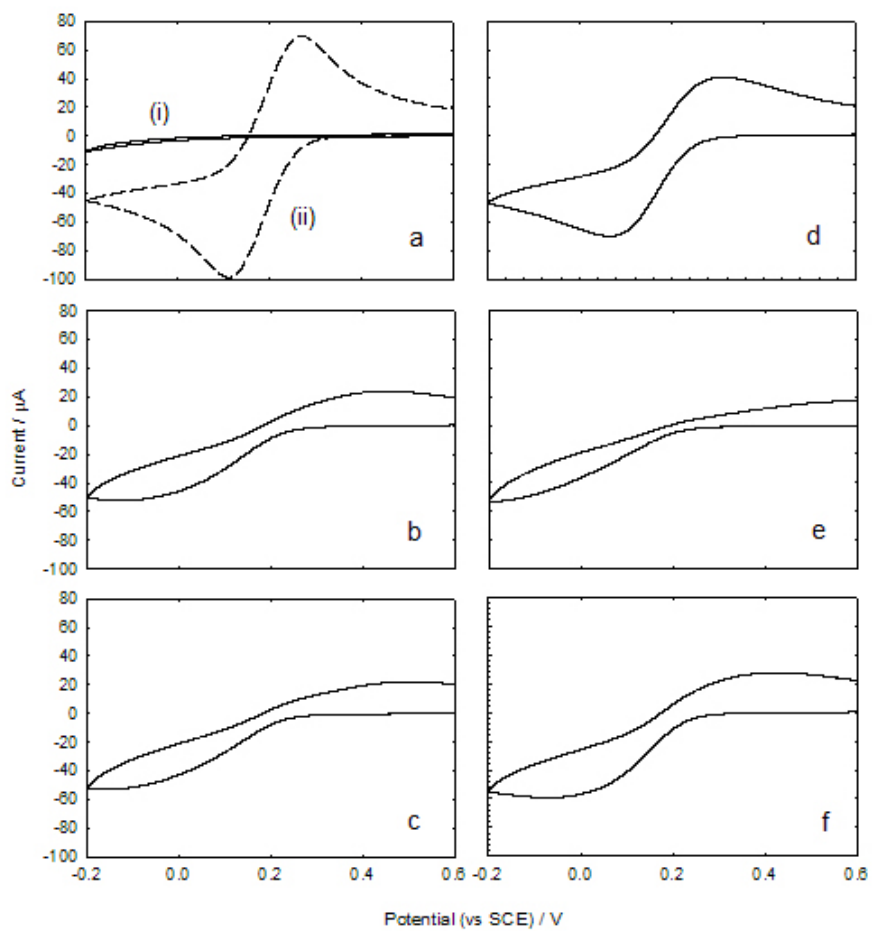

FIG. 3: Cyclic voltammetry in aqueous $4.5 \mathrm{mM} \mathrm{Fe}(\mathrm{CN})_{6}^{3-}$ $+0.1 \mathrm{M} \mathrm{KCl}$ (a) at (i) NP-modified GC using modification time of $600 \mathrm{~s}$ and (ii) polished GC; (b) NP-modified GC after 2 cycles to $-1.3 \mathrm{~V}$ in $0.25 \mathrm{M} \mathrm{H}_{2} \mathrm{SO}_{4}$; (c) after holding the potential at $E_{a p p}=E_{p, c}-150 \mathrm{mV}$ for $600 \mathrm{~s}$ in acetonitrileelectrolyte solution; (d) after a further 18 cycles to $-1.3 \mathrm{~V}$ in $0.25 \mathrm{M} \mathrm{H}_{2} \mathrm{SO}_{4}$; (e) re-applying a potential of $1.5 \mathrm{~V}$ for 300 $\mathrm{S}$ in acetonitrile-electrolyte solution; (f) subsequent treatment in $0.25 \mathrm{M} \mathrm{H}_{2} \mathrm{SO}_{4}$ for another 2 cycles.

\section{RESULTS AND DISCUSSION}

Figure 1 shows the cyclic voltammogram for the reduction of 4-nitrobenzene diazonium tetrafluoroborate in acetonitrile at a pyrolyzed photoresist film (PPF) electrode. The voltammogram shows a chemically irreversible process during electrochemical reduction. The cathodic peak in the subsequent scans exhibits a decrease in current size and disappears completely after the third scan. This is consistent with the behavior of a modified electrode where the blocking of the surface is due to the formation of a grafted layer. The response of PPF is similar to the behavior observed on glassy carbon electrodes previously. PPF and GC have previously been shown to have similar characteristics as electrode materials for solution species undergoing simple outer-sphere electron transfer, and as a surface for diazonium coupling reactions [8]. For experimental practicality, voltammetric analysis was performed at GC substrates while AFM measurements were performed on PPF surfaces. The attachment of the nitrophenyl (NP) layer occurs via a coupling mechanism that is well-reported, involving the generation of a radical close to the electrode which leads to its grafting to the interface according to Eq. (1) [9]. The standard conditions adopted involved generating films with constant potential electrolysis, applying a modifying potential $\left(E_{a p p}\right)$ of 
$E_{a p p}=E_{p, c}-150 \mathrm{mV}$, where $E_{p, c}$ is the potential of cathodic peak of the modifier (Fig 1). This value was chosen to allow a reasonable rate of surface modification without use of excessive overpotential that has been related to the uncontrolled generation of very thick films.

Carbon Surface $+{ }^{+} \mathrm{N}_{2}-\mathrm{C}_{6} \mathrm{H}_{4}-\mathrm{NO}_{2}+e^{-} \rightarrow$ Carbon Surface- $\mathrm{C}_{6} \mathrm{H}_{4}-\mathrm{NO}_{2}+\mathrm{N}_{2}$.

Nitroaromatic groups are electroactive and thus their films can be monitored electrochemically via voltammetry of the modified surfaces. The NP electroactivity can be observed in both aqueous and non-aqueous conditions. Under non-aqueous conditions, the NP group is reversibly reduced by a one electron process, and in aqueous acidic conditions, the NP group is irreversibly reduced to hydroxyaminophenyl and aminophenyl groups via a multielectron process described by Eq. (2) [10]. In this work, the PPF surfaces were modified in acetonitrile and the NP-grafted film was subsequently examined in aqueous sulfuric acid. Figure 2 shows the cyclic voltammogram of a NP-modified PPF surface in aqueous $0.25 \mathrm{M}$ $\mathrm{H}_{2} \mathrm{SO}_{4}$. The electrochemical response of the NP-film reveals a multielectron process. The large reduction peak at $\sim-0.85 \mathrm{~V}$ in the first scan, which disappears in the second cycle, has previously been assigned to the reduction of nitro groups by reactions in Eqs. (2a) and (2c). The broad oxidation peaks between $0.2 \mathrm{~V}$ and $0.6 \mathrm{~V}$ and their associated reduction peaks were previously assigned to the hydroxylamine/nitroso redox couple described in Eq. (2b), which comes from the incomplete reduction of a fraction of nitro groups. Quantitative evaluation of the peak areas in the cyclic voltammograms can give information about the surface coverage of NP groups grafted at the electrode. For grafting times between 10 and $300 \mathrm{~s}$, the surface coverage is between 0.5 and $2.3 \times 10^{-9} \mathrm{~mol} / \mathrm{cm}^{2}$ (based on the geometric area of the electrode). These values are consistent with estimates in other reports using similar modification conditions [11].

$$
\begin{array}{r}
\text { Carbon Surface- } \mathrm{C}_{6} \mathrm{H}_{4}-\mathrm{NO}_{2}+4 \mathrm{H}^{+}+4 e^{-} \rightarrow \text { Carbon Surface- } \mathrm{C}_{6} \mathrm{H}_{4}-\mathrm{NHOH}+\mathrm{H}_{2} \mathrm{O}, \\
\text { Carbon Surface- } \mathrm{C}_{6} \mathrm{H}_{4}-\mathrm{NHOH} \leftrightarrow \text { Carbon Surface- } \mathrm{C}_{6} \mathrm{H}_{4}-\mathrm{NO}+2 \mathrm{H}^{+}+2 e^{-}, \\
\text {Carbon Surface- } \mathrm{C}_{6} \mathrm{H}_{4}-\mathrm{NHOH}+2 \mathrm{H}^{+}+2 e^{-} \rightarrow \text { Carbon Surface- } \mathrm{C}_{6} \mathrm{H}_{4}-\mathrm{NH}_{2}+\mathrm{H}_{2} \mathrm{O} .
\end{array}
$$

Figure 3 shows voltammograms of $\mathrm{Fe}(\mathrm{CN})_{6}^{3-}$ obtained at a NP-modified GC surface subjected to different electrochemical treatments. Voltammetric probing with the $\mathrm{Fe}(\mathrm{CN})_{6}^{3-} / \mathrm{Fe}(\mathrm{CN})_{6}^{4-}$ redox couple at the as-formed NPmodified surface shows that the electrode response is consistent with very slow apparent electron transfer kinetics due to the blocking effects and physical barrier imposed by the grafted NP film (Figs. 3a, i). Also shown in Fig. $3(\mathrm{a})$ is the response of $\mathrm{Fe}(\mathrm{CN})^{3-}$ at a polished GC electrode (scan ii). After transferring the film to aqueous $\mathrm{H}_{2} \mathrm{SO}_{4}$ acid solution and two potential scans to $-1.3 \mathrm{~V}$ to electrochemically reduce the NP group, the voltammetric response of $\mathrm{Fe}(\mathrm{CN})_{6}^{3-}$ is markedly increased (Fig. $3 \mathrm{~b})$. These results indicate that the scans to negative potential generate film properties that allow the $\mathrm{Fe}(\mathrm{CN})_{6}^{3-}$ redox species to undergo redox reaction at the modified electrode. This is not just a solvent effect, since returning the treated electrode to acetonitrile electrolyte solutions under film-preparation conditions did not change the $\mathrm{Fe}(\mathrm{CN})_{6}^{3-}$ response (Fig. 3c). Hence other effects related to potential must be operative here. The modified electrode exhibits much faster electron-transfer kinetics, approaching those observed at a bare GC electrode, after further negative potential cycling (18 cycles) in aqueous acid to $-1.3 \mathrm{~V}$ (Fig. 3d). In addition, the observed effect of increase and decrease in $\mathrm{Fe}(\mathrm{CN})_{6}^{3-}$ electron-transfer ki- netics at the modified electrode is reversible. Re-applying a potential of $1.5 \mathrm{~V}$ in acetonitrile-electrolyte solution suppressed the $\mathrm{Fe}(\mathrm{CN})_{6}^{3-}$ response (Fig. 3e). As a final step, the surface was potential scanned in aqueous acid solution between $0.7 \mathrm{~V}$ and $-1.3 \mathrm{~V}$ for two cycles and the $\mathrm{Fe}(\mathrm{CN}){ }_{6}^{3}$ response returns to those observed prior (Fig. 3f). The sequence of experiments suggests that the observed behavior is unlikely to be related to the increase in film hydrophilicity after reduction of the NP groups since hydrophilicity changes are not expected to be reversible. A tentative explanation is that the applied conditions change the electronic properties of the NP-modified carbon electrode such that it can either promote or retard electron-transfer at the interface (see below).

Further insight into the films can be gained using an AFM scratching method to measure the thickness of the NP films at PPF. Figure 4 (bottom) shows an AFM image of a NP-modified PPF surface with a trench scratched out by the AFM tip. Figure 4 (top) illustrates an average cross-sectional profile for the trench. NP film thickness was determined from the statistical average of data points collected in the average cross-sectional profile of two trenches created at random locations on the film. Asprepared films had thicknesses ranging from 1.5 to $4.3 \mathrm{~nm}$ (Table 1). Assuming the average molecular orientation of the film is perpendicular to the PPF surface and the 

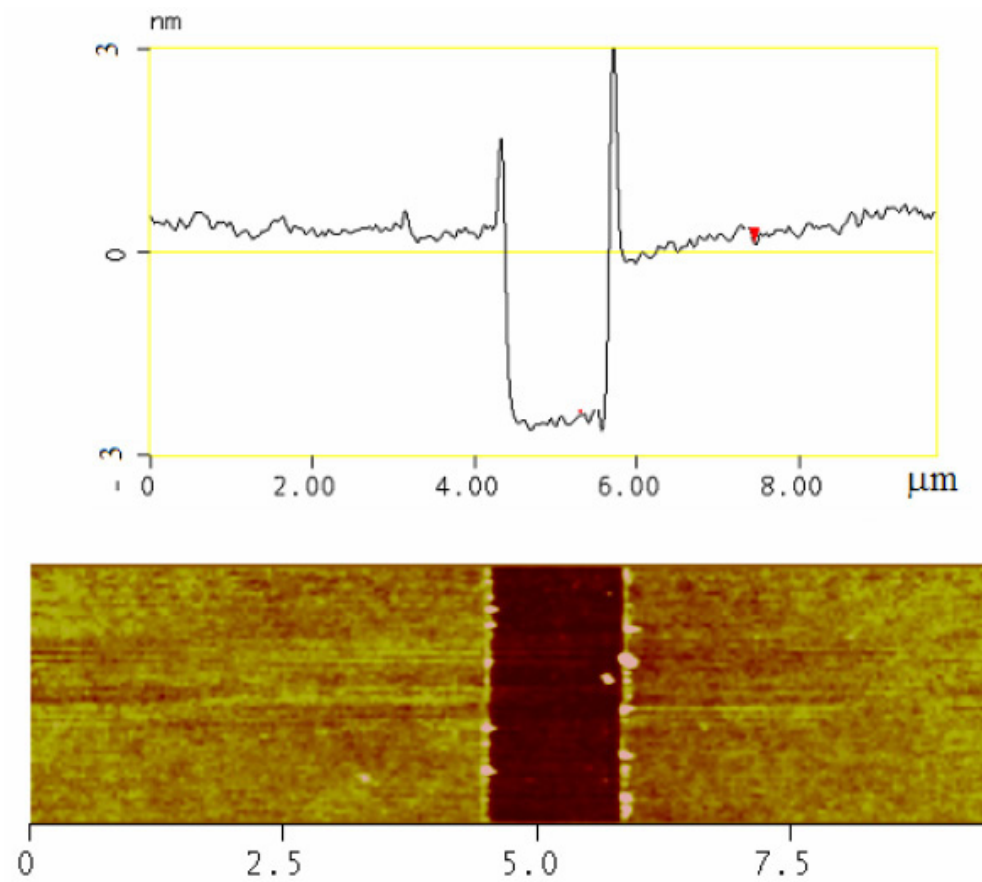

2.5

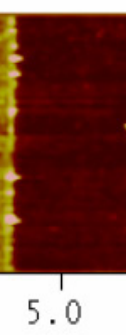

5.0

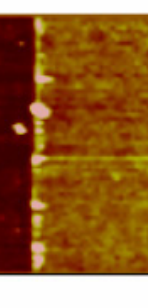

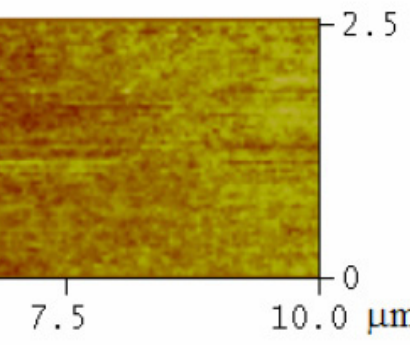

\section{Height}

$6.0 \mathrm{~nm}$

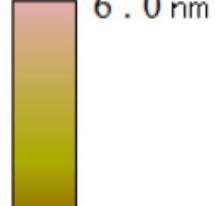

$3.0 \mathrm{~nm}$

$0.0 \mathrm{~nm}$

FIG. 4: (bottom) AFM image $(10 \mu \mathrm{m} \times 2.5 \mu \mathrm{m})$ of a NP film at PPF with a section of the film removed. The NP film was generated in $5 \mathrm{mM} \mathrm{NP}$ diazonium $+0.1 \mathrm{M}\left[\mathrm{Bu}_{4} \mathrm{~N}\right] \mathrm{BF}_{4}$ acetonitrile solution at $E_{a p p}=E_{p, c}-150 \mathrm{mV}$ for $180 \mathrm{~s}$. (top) A cross-sectional plot of the image showing the average film height profile of the scratch.

TABLE I: NP-film thickness at PPF substrate before and after electrochemical reduction in acid, and surface coverage of electroactive NP groups. ${ }^{a}$ Prepared in $1 \mathrm{mM}$ NP diazonium +0.1 $\mathrm{M}\left[\mathrm{Bu}_{4} \mathrm{~N}\right] \mathrm{BF}_{4}$ acetonitrile solution. ${ }^{b}$ Prepared in $5 \mathrm{mM}$ diazonium $+0.1 \mathrm{M}\left[\mathrm{Bu}_{4} \mathrm{~N}\right] \mathrm{BF}_{4}$ acetonitrile solution. ${ }^{c}$ two potential cycles $(0.7$ to $-1.3 \mathrm{~V})$ in $0.25 \mathrm{M} \mathrm{H}_{2} \mathrm{SO}_{4}$

\begin{tabular}{cccc}
\hline $\begin{array}{c}\text { Modification } \\
\text { Time } \\
(\mathrm{s})\end{array}$ & $\begin{array}{c}\text { As-prepared } \\
\text { thickness } \\
(\mathrm{nm})\end{array}$ & $\begin{array}{c}\text { Thickness } \\
\text { after Acid } \\
\text { Reduction }\end{array}$ & $\begin{array}{c}\text { Surface } \\
\text { Coverage }\end{array}$ \\
\hline $30^{b}$ & 2.1 & 1.8 & 1.6 \\
$120^{b}$ & 3.4 & 2.0 & 0.8 \\
$120^{b}$ & 3.2 & 1.7 & 6.8 \\
$180^{b}$ & 3.1 & 2.0 & 1.4 \\
$300^{b}$ & 3.7 & 3.0 & 0.5 \\
$300^{b}$ & 3.8 & 2.2 & 1.9 \\
$300^{b}$ & 3.1 & 2.4 & 1.7 \\
$10^{a}$ & 1.6 & 1.0 & 1.6 \\
$10^{a}$ & 1.5 & 0.7 & 1.6 \\
$30^{a}$ & 1.6 & 1.0 & 1.9 \\
$300^{a}$ & 4.1 & 2.9 & 2.3 \\
$300^{a}$ & 4.3 & 3.6 & 2.3 \\
\hline \hline
\end{tabular}

length of the NP modifier is $0.66 \mathrm{~nm}$ (based on the optimization of the structure using Spartan software), the NP films correspond to a molecular height of between 2 and 7 layers, i.e.: they have a multilayered structure. After reduction in aqueous acid, AFM measurements revealed that film thickness decreases between 15 and $50 \%$.

To probe the reversibility of film changes, a NP-grafted surface was potential cycled twice to $-1.3 \mathrm{~V}$ in aqueous acid and examined using AFM. The film was then re- turned to $0.1 \mathrm{M}\left[\mathrm{Bu}_{4} \mathrm{~N}\right] \mathrm{BF}_{4}$-acetonitrile solution and the potential used for film preparation, i.e. $E_{a p p}=E_{p, c}-150$ $\mathrm{mV}$, was re-applied for $300 \mathrm{~s}$. After this treatment, the film thickness returned to close the initial as-prepared thickness (Table 2). This demonstrates that the change in film thickness is reversible (within experimental uncertainty) and indicates that there is not a large-scale loss of film. However, scans in the probe solution showed no change to $\mathrm{Fe}(\mathrm{CN})_{6}^{3-}$ voltammetry after returning the treated electrode back to film preparation conditions in acetonitrile-electrolyte solution (see above). For the modified electrode treated as described above, applying a potential $1.5 \mathrm{~V}$ in acetonitrile-electrolyte solution recovers the blocking effect of the NP film towards redox probe $\mathrm{Fe}(\mathrm{CN})_{6}^{3-}$, while AFM measurements reveal relatively little change in film thickness. Thus, AFM shows that it is unlikely that changes in $\mathrm{Fe}(\mathrm{CN})_{6}^{3-}$ response is from film desorption, although nanometer-size pinhole formation cannot be discounted due to the lateral resolution limits of the AFM instrument (in the order of $\sim 10 \mathrm{~nm}$ ). More experiments are currently underway to investigate the effect of applied potential influence on film properties.

The film thickness changes observed in this work are consistent with potential-induced swelling and compaction processes, similar to those recently reported for nitroazobenzene [11] and carboxylate-derived arylmethyl systems [12]. The process involved is likely to be a combination of solvation and potential-induced effects related to solvent and ion penetration occurring within the film. Entrained solvent ions can migrate in and out of the NPfilm, possibly from a concentration gradient set up in the different solvent environments, which is likely to be influenced by potential cycling. On transfer to acidic conditions, rearrangement of the film is expected to minimize 
TABLE II: NP film thickness at PPF substrate after various treatments. Treatments were applied as shown in descending order in the Table. ${ }^{a}$ treated in the presence of $0.1 \mathrm{M}\left[\mathrm{Bu}_{4} \mathrm{~N}\right] \mathrm{BF}_{4}$ supporting electrolyte.

\begin{tabular}{|c|c|c|c|}
\hline NP Film treatment & Conditions & Applied Potential, time & Thickness (nm) \\
\hline As-prepared & $1 \mathrm{mM}$ NP diazonium ${ }^{a}$ & $E_{a p p}=E_{p, c}-150 \mathrm{mV}, 600 \mathrm{~s}$ & 4.1 \\
\hline Acid reduction & $0.25 \mathrm{M} \mathrm{H}_{2} \mathrm{SO}_{4}$ & 2 cycles $0.7 \mathrm{~V}$ to $-1.3 \mathrm{~V}$ & 2.9 \\
\hline Film-prep conditions & Acetonitrile $^{a}$ & $E_{a p p}=E_{p, c}-150 \mathrm{mV}, 600 \mathrm{~s}$ & 3.8 \\
\hline Positive applied potential & Acetonitrile $^{a}$ & $1.5 \mathrm{~V}, 600 \mathrm{~s}$ & 3.6 \\
\hline
\end{tabular}

the exposure of hydrophobic film components in aqueous conditions.

Considering the origin of the changes in probe response, it appears that the apparent rate of electron-transfer does not correlate with the film thickness changes illustrated in this work. The observations that the film remains stable and largely intact under the described treatments, suggests the most likely explanation for the apparent changes in barrier properties of the film is a mechanism involving a change in the electronic structure of the system. McCreery et al observed similar changes to the apparent rate of electron transfer for probe species at their diazoniumgenerated monolayer films, after negative potential scans in acetonitrile solution [13]. Those workers proposed a conductance switching mechanism in which electrons from the GC substrate is injected into the monolayers containing biphenyl and nitrobiphenyl groups, which may lead to a quinoid structure in the film, resulting in a smaller HOMO-LUMO gap and higher electronic conductance. These potential-induced structural changes in the film result in increased rates of electron tunneling and hence promote electron-transfer across the interface. Our observations of film behavior in this work are consistent to this hypothesis and we tentatively suggest that a conductance switching mechanism is operative here. Nevertheless, the origin of the potential-induced effects remains under active investigation and further experiments are currently underway.

\section{CONCLUSIONS}

In conclusion, we observed in this preliminary investigation that as-prepared NP films dramatically reduce the apparent rate constant for electron transfer to solution redox species but after treatment at negative potentials, the voltammetric response increases, and leads to a decrease in film thickness. These changes can be reversed by application of positive potentials. AFM analysis reveals that the multilayered films are largely intact after positive and negative potential excursions in acetonitrile and aqueous acid. The observations of film behavior suggest that a conductance-switching mechanism is operative, where applied potential induces structural and electronic changes. Further investigations are underway to confirm this mechanism.

\section{Acknowledgments}

This work was supported by the Tertiary Education Commission and the MacDiarmid Institute for Advanced Materials and Nanotechnology. We thank Dr. Richard Blaikie and Dr. Paula Brooksby for their assistance in the work. S. S. C. Yu thanks Dr. John Loring for use of Linkfit curve fitting software.
[1] B. Barbier, J. Pinson, G. Desarmot, M. Sanchez, J. Electrochem. Soc. 137, 1757 (1990).

[2] P. Allongue, M. Bernard, J. Pinson, C. de Villeneuve, J. Phys Chem. 101, 2415 (1997).

[3] A. Adenier, M. Bernard, M. Chehimi, E. Deliry, B. Desbat, O. Fagebaume, J. Pinson, F. Podvorica. J. Am. Chem. Soc. 123, 4541 (2001).

[4] R. McCreery, Chem.Mater. 16, 4477 (2004).

[5] C. Dyke, J. Tour, Nano. Lett. 3, 1215 (2003), and references therein.

[6] K. Balasubramanian, M. Burghard, Small 1, 180 (2005).

[7] P. Brooksby, A. Downard, Langmuir 20, 5038 (2004).

[8] S. Ranganathan, R. McCreery, Anal. Chem. 73, 893
(2001).

[9] P. Allongue, M. Delamar, B. Desbat, O. Fagebaume, R. Hitmi, J. Pinson, J. Savéant, J. Am. Chem. Soc. 119, 201 (1997).

[10] B. Ortiz, C. Champagne, G. Belanger, J. Electroanal. Chem. 455, 75 (1998).

[11] P. Brooksby, A. Downard, J. Phys. Chem. B 109, 8791 (2005).

[12] P. Brooksby, A. Downard, S. Yu, Langmuir, submitted.

[13] A. Solak, L. Eichorst, W. Clark, R. McCreery, Anal. Chem. 75, 296 (2003). 